Laporan Penelitian

\title{
Validitas dan reliabilitas EORTC QLQ-H\&N35 sebagai alat ukur kualitas hidup penderita kanker kepala leher
}

\author{
Rahmaeni, Freddy Kuhuwael, Sutji Pratiwi Rahardjo \\ Bagian Ilmu Kesehatan Telinga Hidung Tenggorok - Bedah Kepala Leher \\ Fakultas Kedokteran Universitas Hasanuddin/Rumah Sakit Dr. Wahidin Sudirohusodo \\ Makassar
}

\begin{abstract}
ABSTRAK
Latar Belakang: Saat ini belum ada alat yang valid dan reliabel untuk mengukur kualitas hidup penderita kanker kepala leher di Indonesia. Tujuan: Menilai validitas dan reliabilitas dari EORTC QLQ-H\&N35 sebagai alat ukur kualitas hidup penderita kanker kepala leher di Makassar. Metode: Jenis penelitian ini adalah observasional analitik dengan pendekatan cross-sectional. Penelitian ini dilakukan pada bulan September-November 2013. Populasi penelitian adalah semua kasus kanker kepala leher yang datang berobat ke Bagian Ilmu Kesehatan THT-KL, Rumah Sakit Dr. Wahidin Sudirohusodo Makassar. Sampel sebanyak 60 orang dipilih secara purposive, yakni penderita kanker kepala leher yang belum menjalani terapi, sementara terapi, dan telah selesai terapi. Pengukuran kualitas hidup menggunakan European Organization for Research and Treatment of Cancer - Head and Neck Cancer Quality of Life Questionnaire (EORTC QLQ-H\&N35) yang sebelumnya sudah dilakukan uji validitas dan reliabilitas terlebih dahulu melalui validasi transcultural menurut WHO (World Health Organzation). Hasil: Pada uji validitas didapatkan korelasi bermakna pada hampir semua skala gejala, sedangkan pada uji reliabilitas hasil penilaian EORTC QLQ-H\&N35 dengan adaptasi bahasa Indonesia ini mempunyai nilai reliabilitas yang sangat baik dengan nilai Cronbach- $\alpha>0,7$. Kesimpulan: Instrumen EORTC QLQ-H\&N35 dengan adaptasi bahasa Indonesia adalah valid dan reliabel untuk mengukur kualitas hidup penderita kanker kepala leher di Bagian THT-KL RS Dr. Wahidin Sudirohusodo Makassar.
\end{abstract}

Kata kunci: validitas, reliabilitas, EORTC QLQ-H\&N35

\section{ABSTRACT}

Background: The lack of measurement tools which is valid and reliable for evaluating the quality of life of patients with head neck cancer in Indonesia. Purpose: To assess the validity and reliability of the EORTC QLQ-H\&N35 as a tool to measure the quality of life of patients with head and neck cancer in Makassar. Methods: This study was an observational analytic cross-sectional approach. This research was conducted during September - November 2013. The population was all head and neck cancer cases who came for treatment to the ENT Department Dr. Wahidin Sudirohusodo hospital. Sample of 60 people were selected purposively. Assessment of quality of life used the European Organization for Research and Treatment of Cancer - Head and Neck Cancer Quality of Life Questionnaire (EORTC QLQ-H\&N35) after the validity and reliability tests was conducted transcultural validation in Indonesian language adaptation according to the WHO. Results: On the validity of the test, it showed significant correlation in almost all scales of symptoms, while on reliability test results of the EORTC QLQ-H\&N35 assessment, it was excellent with values of Cronbach- $\alpha>0,7$. Conclusion: The Indonesian adaptation EORTC QLQ-H\&N35 was found as valid and reliable instrument for assessing the quality of life of patients with head and neck cancer in ENT Department, Dr. Wahidin Sudirohusodo Hospital in Makassar.

Keywords : validity, reliability, EORTC QLQ-H7N35

Alamat korespondensi: dr. Rahmaeni. Alamat: Kompleks UNHAS Jl.Sastra Raya A/44 Antang, Makassar. Telp: 0411-590737.Email: tht_fkunhas@yahoo.com; rahmaenibuhari@yahoo.com 


\section{PENDAHULUAN}

Kanker kepala leher adalah berbagai jenis tumor ganas yang secara spesifik mengenai traktus aerodigestif yang letaknya dari dasar tengkorak sampai bagian bawah laring, dari anterior kavum nasi dan bibir sampai posterior faring. Kanker kepala leher mempunyai kesamaan dalam hal etiologi, cara penyebaran, metode pemeriksaan, diagnostik, pengobatan, dan rehabilitasi. Pada umumnya tumor ganas THT-KL ditemukan pada rongga mulut, orofaring, nasofaring, hidung, dan sinus paranasal, hipofaring, laring, dan telinga. ${ }^{1}$

Kuhuwael $^{2}$ melaporkan bahwa di RSU Dadi dan RS Dr. Wahidin Sudirohusodo selama periode 10 tahun (1990-1999) telah ditemukan 274 (47,98\%) kasus karsinoma nasofaring dari seluruh tumor ganas kepala leher dengan perbandingan antara laki-laki dan wanita 2,6:1. Ronis ${ }^{3}$ melaporkan bahwa terjadi perubahan kualitas hidup pada pasien kanker kepala leher berupa keluhan fisik seperti nyeri pada daerah leher dan kepala, menurunnya daya penglihatan, gangguan indra pengecapan dan penciuman, kurangnya nafsu makan, rambut rontok, mulut pahit, dan sulit menelan.

Di Indonesia secara umum belum ada alat ukur yang valid dan reliabel untuk mengevaluasi kualitas hidup penderita kanker kepala leher, namun di luar negeri telah dikenal, dipakai secara luas dan dianggap efektif, salah satunya adalah European Organization For Research And Treatment Of Cancer Head and Neck Cancer Quality of Life Questionnaire (EORTC QLQ-H\&N35). Alat ukur tersebut merupakan kuesioner yang secara spesifik diperuntukkan penderita kanker kepala leher yang terdiri dari 7 skala gejala (nyeri, menelan, masalah indera, masalah bicara, masalah makan, interaksi sosial, dan seksualitas) dan 6 kuesioner tunggal (masalah gigi, masalah membuka mulut lebar, mulut kering, ludah kental, batuk, dan perasaan sakit). ${ }^{4}$ Beberapa penelitian sebelumnya membuktikan bahwa EORTC QLQ-H\&N35 mempunyai kemampuan untuk menilai perbedaan status tampilan, modalitas terapi, lokasi penyakit, dan stadium. Pada penelitian yang dilakukan oleh Aaronson ${ }^{5}$ didapatkan bahwa EORTC QLQ-H\&N35 mempunyai validasi yang baik dan lebih sensitif dalam mendeteksi perbedaan gejalagejala penyakit pada stadium dini sampai lanjut dibanding dengan kuesioner kualitas hidup yang lain.

Kuesioner EORTC QLQ-H\&N35 berasal dari negeri dan budaya yang berbeda dengan negara Indonesia, maka sebelum digunakan pada masyarakat luas harus dilakukan uji validitas dan reliabilitasnya terlebih dahulu. Menurut aturan WHO (World Health Organization) ada tahapan yang harus dilakukan dalam melakukan validasi suatu tes antar bangsa, sehingga tes ini dapat diterima untuk dilakukan di suatu negara yang berbeda bahasa dan budaya. ${ }^{6}$

Tujuan penelitian ini adalah untuk menilai validitas dan reliabilitas dari EORTC QLQ-H\&N35 sebagai alat ukur kualitas hidup penderita kanker kepala leher di Makassar.

\section{METODE}

Penelitian adalah observasional analitik dengan pendekatan cross-sectional. Penelitian dilakukan sejak September sampai November 2013. Populasi adalah semua penderita kanker kepala leher yang datang berobat ke Bagian Ilmu Kesehatan THT-KL RS Dr. Wahidin Sudirohusodo di Makassar. Sampel penelitian adalah penderita kanker kepala leher yang belum mendapat terapi, sementara terapi, dan telah menjalani terapi, serta memenuhi kriteria penelitian. Cara pengambilan sampel yaitu secara purposive dengan jumlah sampel 60 orang. Kriteria eksklusi adalah penderita tidak kooperatif (tidak sadar, tidak bisa baca tulis, dan tidak mengerti bahasa Indonesia) dan penderita karsinoma nasofaring dengan komorbid yang berat. 
Sebelum dilakukan pengisian kuesioner oleh sampel, dilakukan proses validasi transcultural menurut WHO yang terdiri dari 7 langkah, yakni: 1. Membentuk 3 kelompok ahli penerjemah; 2. Menilai struktur konsep perangkat yang dilakukan oleh tim ahli materi; 3. Kuesioner diterjemahkan ke dalam bahasa Indonesia 4. Penilaian hasil terjemahan tersebut oleh tim ahli materi; 5. Menilai hasil terjemahan tersebut oleh ahli bahasa kedua; 6. Terjemahan yang sudah dikoreksi oleh tim ahli bahasa dan ahli materi, diterjemahkan kembali ke dalam bahasa Inggris oleh penerjemah yang berbeda; 7. Menilai penerjemahan ulang tersebut oleh para ahli materi dan bahasa dan kemudian dilakukan uji validitas dan reliabilitas. Penderita yang memenuhi kriteria penelitian diberikan informed consent dan diminta mengisi kuesioner EORTC QLQ-H\&N35 yang telah dilakukan uji validasi transcultural. Hasil yang diperoleh kemudian dilakukan uji validitas dengan uji Spearman correlation coefficient dengan nilai $r$ dan mengukur korelasi antara butirbutir pertanyaan dengan skor pertanyaan secara keseluruhan. Nilai signifikan $p<0,010$ menunjukkan bahwa butir pertanyaan yang diuji tersebut adalah valid, sedangkan uji reliabilitas dengan Cronbach- $\alpha$ dan dikatakan reliabel jika memiliki nilai alpha minimal 0,7.

\section{HASIL}

Tabel 1. Karakteristik sampel

\begin{tabular}{|c|c|c|c|}
\hline Karakteristik & & $\begin{array}{c}\text { Kasus } \\
n=60\end{array}$ & $\%$ \\
\hline Jenis kelamin & $\begin{array}{l}\text { Laki-Laki } \\
\text { Perempuan }\end{array}$ & $\begin{array}{l}47 \\
13\end{array}$ & $\begin{array}{l}78,3 \\
21,7\end{array}$ \\
\hline Usia (tahun) & $\begin{array}{l}10-19 \\
20-29 \\
30-39 \\
40-49 \\
50-59 \\
>60\end{array}$ & $\begin{array}{r}3 \\
8 \\
14 \\
14 \\
15 \\
5\end{array}$ & $\begin{array}{r}5,0 \\
13,3 \\
23,3 \\
23,3 \\
25,0 \\
8,3\end{array}$ \\
\hline Pendidikan & $\begin{array}{l}\text { SD } \\
\text { SLTP } \\
\text { SLTA } \\
\text { D3/S1 }\end{array}$ & $\begin{array}{r}2 \\
21 \\
25 \\
12\end{array}$ & $\begin{array}{r}3,3 \\
35 \\
41,7 \\
20,0\end{array}$ \\
\hline Diagnosis & $\begin{array}{l}\text { Karsinoma nasofaring } \\
\text { Karsinoma sinonasal } \\
\text { Karsinoma lidah } \\
\text { Karsinoma laring }\end{array}$ & $\begin{array}{r}43 \\
14 \\
1 \\
2\end{array}$ & $\begin{array}{r}71,7 \\
23,3 \\
1,7 \\
3,3\end{array}$ \\
\hline Histopatologi & $\begin{array}{l}\text { WHO tipe III } \\
\text { WHO tipe II } \\
\text { WHO tipe I } \\
\text { Adenocarcinoma } \\
\text { HPC } \\
\text { Adenoid cystic carsinoma }\end{array}$ & $\begin{array}{r}32 \\
17 \\
7 \\
2 \\
1 \\
1\end{array}$ & $\begin{array}{r}53,3 \\
28,3 \\
11,7 \\
3,3 \\
1,7 \\
1,7\end{array}$ \\
\hline Stadium & $\begin{array}{l}\text { Awal } \\
\text { Lanjut }\end{array}$ & $\begin{array}{l}10 \\
50\end{array}$ & $\begin{array}{l}16,7 \\
83,3\end{array}$ \\
\hline Terapi & $\begin{array}{l}\text { Radioterapi } \\
\text { Kemoterapi } \\
\text { Operasi } \\
\text { Konkomitan }\end{array}$ & $\begin{array}{r}9 \\
34 \\
15 \\
2\end{array}$ & $\begin{array}{r}15,0 \\
56,7 \\
25,0 \\
3,3\end{array}$ \\
\hline
\end{tabular}


Hasil penelitian menunjukkan bahwa penderita kanker kepala leher terbanyak ditemukan pada laki-laki (78,3\%), kelompok usia 50-59 tahun (25\%), dan pada penderita dengan tingkat pendidikan SLTA (25\%).
Jenis kanker kepala leher terbanyak adalah karsinoma nasofaring $(71,7 \%)$, serta jenis histopatologi terbanyak adalah WHO tipe III $(53,3 \%)$, sedangkan stadium lanjut merupakan stadium yang terbanyak $(79,4 \%)$.

Tabel 2. Uji validitas dengan koefisien korelasi Spearman kuesioner EORTC QLQ - H\&N35 adaptasi bahasa Indonesia skala total

\begin{tabular}{|c|c|c|c|}
\hline $\begin{array}{r}\text { Skala } \\
\end{array}$ & & $\mathbf{r}$ & $\mathbf{p}$ \\
\hline \multirow[t]{4}{*}{ Nyeri (HNPA) } & HN1 & $0,375 * *$ & 0,003 \\
\hline & HN2 & $0,338 * *$ & 0,008 \\
\hline & HN3 & $0,805 * *$ & 0,000 \\
\hline & HN4 & $0,500 * *$ & 0,000 \\
\hline \multirow[t]{4}{*}{ Menelan (HNSW) } & HN5 & $0,654 * *$ & 0,000 \\
\hline & HN6 & $0,830 * *$ & 0,000 \\
\hline & HN7 & $0,721 * *$ & 0,000 \\
\hline & HN8 & $0,770 * *$ & 0,000 \\
\hline \multirow[t]{2}{*}{ Masalah indera (HNSE) } & HN13 & $0,510 * *$ & 0,000 \\
\hline & HN14 & $0,130 * *$ & 0,007 \\
\hline \multirow[t]{3}{*}{ Masalah bicara (HNSP) } & HN16 & $0,563 * *$ & 0,000 \\
\hline & HN23 & $0,499 * *$ & 0,000 \\
\hline & HN24 & $0,488 * *$ & 0,000 \\
\hline \multirow[t]{4}{*}{ Masalah makan (HNSO) } & HN19 & $0,729 * *$ & 0,000 \\
\hline & HN20 & $0,495 * *$ & 0,000 \\
\hline & HN21 & $0,461 * *$ & 0,000 \\
\hline & HN22 & $0,650 * *$ & 0,000 \\
\hline \multirow[t]{5}{*}{ Interaksi sosial (HNSC) } & HN18 & $0,536 * *$ & 0,000 \\
\hline & HN25 & $0,588 * *$ & 0,000 \\
\hline & HN26 & $0,578 * *$ & 0,000 \\
\hline & HN27 & $0,541 * *$ & 0,000 \\
\hline & HN28 & $0,538 * *$ & 0,000 \\
\hline \multirow[t]{2}{*}{ Masalah seksual (HNSX) } & HN29 & $0,467 * *$ & 0,000 \\
\hline & HN30 & $0,701 * *$ & 0,000 \\
\hline
\end{tabular}

Pada tabel 2 didapatkan hasil masingmasing variabel memberikan hasil yang valid, berarti mempunyai hubungan yang bermakna dengan jumlah skor total $(\mathrm{p}<0,001)$.

Pada tabel 3 menunjukkan bahwa uji reliabilitas tersebut didapatkan skala HNSX mempunyai nilai Cronbach- $\alpha$ yang paling tinggi yaitu $>0,9$ sedangkan skala HNPA, HNSW, HNSP, HNSO, dan HNSC mempunyai nilai masing-masing Cronbach- $\alpha$ $>0,8$ yang berarti mempunyai tingkat reliabilitas baik. Nilai rata-rata skala HNSE mempunyai nilai Cronbach- $\alpha>0,7$ yang berarti tingkat reliabilitas dapat diterima. Menurut Gliem ${ }^{7}$ bila nilai Cronbach- $\alpha>0,7$ berarti hasil penilaian diterima, nilai $>0,8$ mempunyai nilai yang baik, dan nilai $>0,9$ berarti hasil uji yang sangat baik. Sedangkan bila nilai Cronbach- $\alpha>0,6$ maka hasil reliabilitas yang dipertanyakan. Dengan hasil keseluruhan pada uji reliabilitas yang belum merata baik di semua skala maka dilakukan pengujian reliabilitas dengan uji Cronbach- $\alpha$ untuk total item. 
Tabel 3. Uji reliabilitas kuesioner EORTC QLQ-H\&N35 adaptasi bahasa Indonesia

\begin{tabular}{|c|c|c|}
\hline Skala & & Cronbach-a \\
\hline & HN1 & 0,749 \\
\hline \multirow[t]{4}{*}{ Nyeri (HNPA) } & HN2 & 0,824 \\
\hline & HN3 & 0,747 \\
\hline & HN4 & 0,783 \\
\hline & & Cronbach- $\alpha=0,817$ \\
\hline \multirow[t]{5}{*}{ Menelan (HNSW) } & HN5 & 0,795 \\
\hline & HN6 & 0,794 \\
\hline & HN7 & 0,783 \\
\hline & HN8 & 0,812 \\
\hline & & Cronbach- $\alpha=0,837$ \\
\hline \multirow[t]{3}{*}{ Masalah indera (HNSE) } & HN13 & 0,781 \\
\hline & HN14 & 0,849 \\
\hline & & Cronbach- $\alpha=0,794$ \\
\hline \multirow[t]{4}{*}{ Masalah bicara (HNSP) } & HN16 & 0,829 \\
\hline & HN23 & 0,799 \\
\hline & HN24 & 0,784 \\
\hline & & Cronbach- $\alpha=0,846$ \\
\hline \multirow[t]{5}{*}{ Masalah makan (HNSO) } & HN19 & 0,780 \\
\hline & HN20 & 0,800 \\
\hline & HN21 & 0,784 \\
\hline & HN22 & 0,775 \\
\hline & & Cronbach- $\alpha=0,825$ \\
\hline \multirow[t]{6}{*}{ Interaksi sosial (HNSC) } & HN18 & 0,780 \\
\hline & HN25 & 0,787 \\
\hline & HN26 & 0,769 \\
\hline & HN27 & 0,776 \\
\hline & HN28 & 0,777 \\
\hline & & Cronbach- $\alpha=0,813$ \\
\hline \multirow[t]{3}{*}{ Masalah seksual (HNSX) } & HN29 & 0,875 \\
\hline & HN30 & 0,868 \\
\hline & & Cronbach- $\alpha=0,904$ \\
\hline
\end{tabular}

\section{DISKUSI}

Pada penelitian ini didapatkan bahwa jumlah sampel laki-laki lebih banyak daripada perempuan. Sesuai dengan penelitian yang dilaporkan oleh Kuhuwael, ${ }^{2}$ bahwa di RSU Dadi dan RS Dr. Wahidin Sudirohusodo, kasus karsinoma nasofaring dari tumor ganas kepala leher dengan perbandingan antara laki-laki dan wanita 2,6:1. Hasil karakteristik sampel berdasarkan usia pada penelitian ini didapatkan jumlah sampel terbanyak pada kelompok umur 50-59 tahun (25\%) sesuai dengan penelitian Bastiana ${ }^{8}$ yang menyatakan bahwa kanker kepala leher terjadi paling banyak pada usia $<55$ tahun.

Pada penelitian ini sebagian besar sampel berpendidikan sederajat SLTA dan SLTP. Tingginya pendidikan membuat penderita lebih cepat menyadari dan datang lebih awal untuk berobat. Pada penelitian ini didapatkan pula jenis kanker kepala leher yang terbanyak adalah karsinoma nasofaring yaitu 71,7\%. Hal ini sesuai dengan penelitian yang dilakukan oleh Hoffman ${ }^{9}$ tentang insiden kanker kepala leher mendapatkan yang memiliki insiden tertinggi adalah karsinoma nasofaring 478 kasus (28\%), sedangkan berdasarkan gambaran hasil histopatologi WHO (1987), karsinoma sel skuamous tipe 3 terbanyak dengan jumlah 32 kasus $(53,3 \%)$ dan WHO tipe 2 sebanyak 15 kasus (25\%).

Berdasarkan stadium TNM-AJCC (2010) kanker kepala leher terbanyak adalah stadium lanjut yaitu stadium IV sebanyak 29 kasus $(48,3 \%)$. Hal ini sesuai dengan penelitian Kurniawati ${ }^{10}$ dimana penderita 
karsinoma nasofaring terbanyak ditemukan pada stadium IV (33,3\%). Ini disebabkan pada stadium awal, tumor yang masih kecil tidak menimbulkan gejala atau kadangkadang dengan bertambah besarnya tumor, gejala yang terjadi tetap tidak spesifik dan membingungkan sehingga penderita datang bila telah ada pembesaran kelenjar leher dan sudah dalam tahap stadium lanjut.

EORTC QLQ-H\&N35 adalah kuesioner yang dibuat dan dikembangkan dalam bahasa Inggris dan telah diterjemahkan dalam 11 bahasa dan digunakan di berbagai negara. Sebelum digunakan di negara yang tidak berbahasa Inggris seperti Indonesia, diperlukan adaptasi lintas budaya untuk mencegah terjadinya bias. Maka, pertanyaanpertanyaan dalam kuesioner diterjemahkan ke bahasa Indonesia menurut aturan WHO. Pada penelitian ini didapatkan hasil yang valid menurut kaidah validasi transcultural pada EORTC QLQ-H\&N35 adaptasi bahasa Indonesia. ${ }^{11}$

Uji validitas pada penelitian ini dilakukan dengan metode mengukur korelasi antar butirbutir pertanyaan dengan skor pertanyaan secara keseluruhan dan dianalisis dengan Spearman correlation coefficient. Pada penelitian ini didapatkan korelasi bermakna pada hampir semua skala gejala EORTC QLQH\&N35 $(\mathrm{p}<0,010)$ dan uji reliabilitas yang dilakukan adalah uji reliabilitas intraobserver dan konsistensi internal. Hasil penilaian EORTC QLQ-H\&N35 adaptasi bahasa Indonesia ini mempunyai nilai reliabilitas yang sangat baik dengan nilai Cronbach- $\alpha$ $>0,7$. Nilai alpha tertinggi didapatkan pada skala seksual (HNSX) yaitu $>0,9$. Pada skala HNPA, HNSW, HNSO, HNSP, dan HNSC didapatkan nilai alpha $>0,8$ sedangkan pada skala HNSE mempunyai nilai alpha paling rendah yaitu $>0,7$. Hal ini karena sampel penelitian terbanyak adalah sampel yang sementara menjalani terapi sehingga pada saat pengisian kuesioner sampel masih mengalami efek samping dari pengobatan, hal ini sesuai dengan penelitian Bjordal $^{4}$ yang menyatakan bahwa skala HNSX mempunyai nilai alpha yang paling tinggi sedangkan terendah pada skala HNSE. Pada kedua uji reliabilitas didapatkan hasil yang hampir sama, hal ini didukung oleh Nunnaly, dikutip oleh Santos ${ }^{12}$ bahwa nilai alpha sebesar $>0,7$ menggambarkan suatu nilai reliabilitas yang dapat diterima yang berarti bahwa semua pertanyaan dalam kuesioner EORTC QLQH\&N35 dapat diandalkan dan dipercaya.

Penilaian kualitas hidup menggunakan sistem skoring dari 0 sampai 120 , dimana semakin rendah skor maka semakin baik kualitas hidupnya dan semakin tinggi skor maka semakin buruk kualitas hidupnya. Skor $>60$ menunjukkan keadaan yang sudah mengganggu dan bertambah buruk dengan bertambahnya skor.

Dari hasil penelitian ini didapatkan bahwa kuesioner EORTC QLQ-H\&N35 adalah valid dan reliabel sebagai alat ukur kualitas hidup penderita kanker kepala leher di Makassar.

\section{UCAPAN TERIMA KASIH}

Peneliti mengucapkan banyak terima kasih kepada pihak-pihak yang telah membantu terlaksananya penelitian ini khususnya kepada dr. F.G. Kuhuwael, Sp.THT-KL(K), Prof. Dr. dr. Sutji Pratiwi Rahardjo, Sp.THT-KL(K) dan Dr. dr. Ilhamjaya Patellongi, Sp. M.Kes dan teman-teman sejawat peserta PPDS THTKL FK-UNHAS.

\section{DAFTAR PUSTAKA}

1. Sukardja IDG. Onkologi Klinik. Surabaya: Airlangga University Press, 2000. p.111-2.

2. Kuhuwael FG. Aspek klinis karsinoma nasofaring di RSU Dadi dan RS Dr. Wahidin Sudirohusodo tahun 1990-1999. Disampaikan pada Pertemuan Ilmiah Berkala XV. Makassar, Fakultas Kedokteran UNHAS, 2001. 
3. Ronis. Study examines changes in quality of life after head and neck cancer treatment; 2008. Available from: http://www.medscape. com/qualityoflife/08/20/08. 2008.

4. Bjordal K, Ahlner-Elmqvist M, Tollesson E. Development of an European Organization for Research and Treatment of Cancer (EORTC) questionnaire module to be used in quality of life assessments in head and neck cancer patients. EORTC Quality of Life Study Group. Acta Oncology. 1994; (33):879-85.

5. Aaronson NK, Ahmedzai S, Bergman B. The European organization for research and treatment of cancer QLQ-C30: a quality-oflife instrument for use international clinical trials in oncology. J Natl Cancer Inst. 1993; (85) :365-76.

6. Ommeren MU. Validity issues in transcultural epidemiology. Brit J of Psyc. 2003; (182):376-8.

7. Gliem JA, Gliem RR. Calculating, Interpreting, and reporting cronbach alpha reliability coefficient for Likert type scale. In presented at the midwest research to practice confrence in adult, contuining and community education. The Ohio State University, Columbus, OH, 2003.p. 8-10.
8. Bastiana, Kuhuwael FG. Perbandingan kasus kanker kepala leher dalam dua dekade di Makassar. Konas PERHATI XV Makassar. 2001;p.55-6.

9. Hoffman HT, Cooper JS. National cancer database report on cancer of the head and neck: 10-year update1998. Departement of Radiation Oncology. New York, USA. 2008.

10. Kurniawati, Kuhuwael. Penilaian kualitas hidup penderita karsinoma nasofaring berdasarkan Karnofsky Performance Scale, EORTC QLQ-C30 dan EORTC QLQ-H\&N35 di Makassar. Tesis. Makassar: Fakultas kedokteran Universitas Hasanuddin. 2012. p. 48-9

11. Beaton DE, Bombardier C, Guillemin F, Ferraz MB. Guideline for the process of cross-cultural adaptation of self-report measures. Spine. 2000; (24):3186-91.

12. Santos J. Cronbach's Alpha : A tool for assessing the reliability of scales. Extention Journal Inc.1999; 37(2):1007-5315. 


\section{Lampiran 1}

Versi asli kuesioner European Organization For Research And Treatment Of Head and Neck Cancer Quality of Life Questionnaire (EORTC QLQ-H\&N35)

\begin{tabular}{|c|c|c|c|c|c|}
\hline No & Question & $\begin{array}{l}\text { Not at } \\
\text { all (1) }\end{array}$ & $\begin{array}{l}\text { A little } \\
\text { (2) }\end{array}$ & $\begin{array}{l}\text { Quite a } \\
\text { bit (3) }\end{array}$ & $\begin{array}{c}\text { Very } \\
\text { much (4) }\end{array}$ \\
\hline 1 & Have you had pain in your mouth? & & & & \\
\hline 2 & Have you had pain in your jaw? & & & & \\
\hline 3 & Have you had soreness in your mouth? & & & & \\
\hline 4 & Have you had a painfull throat? & & & & \\
\hline 5 & Have you had problems swallowing liquids? & & & & \\
\hline 6 & Have you had problems swallowing pureed food? & & & & \\
\hline 7 & Have you had problems swallowing solid food? & & & & \\
\hline 8 & Have you choked when swallowing? & & & & \\
\hline 9 & Have you had problems with your teeth? & & & & \\
\hline 10 & Have you had problems opening your mouth wide? & & & & \\
\hline 11 & Have you had a dry mouth? & & & & \\
\hline 12 & Have you had sticky saliva? & & & & \\
\hline 13 & Have you had problems with your sense of smell? & & & & \\
\hline 14 & Have you had problems with your sense of taste? & & & & \\
\hline 15 & Have you coughed? & & & & \\
\hline 16 & Have you been hoarse? & & & & \\
\hline 17 & Have you felt ill? & & & & \\
\hline 18 & Have you appearance bothered you? & & & & \\
\hline 19 & Have you had trouble eating? & & & & \\
\hline 20 & Have you had trouble eating in front of your family? & & & & \\
\hline 21 & Have you had trouble eating in front of other people? & & & & \\
\hline 22 & Have you had trouble enjoying your meals? & & & & \\
\hline 23 & Have you had trouble talking to other people? & & & & \\
\hline $\begin{array}{l}24 \\
25\end{array}$ & $\begin{array}{l}\text { Have you had trouble talking on the telephone? } \\
\text { Have you had trouble having social contact with your } \\
\text { family? }\end{array}$ & & & & \\
\hline 26 & Have you had trouble having social contact with friends? & & & & \\
\hline 27 & $\begin{array}{l}\text { Have you had trouble going out in public? } \\
\text { Have you had trouble having physical } \\
\text { contact with family or friends? }\end{array}$ & & & & \\
\hline \multirow[t]{2}{*}{30} & $\begin{array}{l}\text { Have you felt less interest in sex? } \\
\text { Have you felt less sexual enjoyment? }\end{array}$ & & & & \\
\hline & & No $(1)$ & & Yes $(2)$ & \\
\hline 31 & Have you used pain-killers? & & & & \\
\hline 32 & $\begin{array}{l}\text { Have you taken any nutritional supplements (excluding } \\
\text { vitamins)? }\end{array}$ & & & & \\
\hline 33 & Have you used a feeding tube? & & & & \\
\hline 34 & Have you lost weight? & & & & \\
\hline 35 & Have you gained weight? & & & & \\
\hline
\end{tabular}




\section{Lampiran 2}

\section{Kuesioner EORTC QLQ-H\&N35 adaptasi bahasa Indonesia}

\begin{tabular}{|c|c|c|c|c|c|}
\hline No & Pertanyaan & $\begin{array}{c}\text { Tidak } \\
\text { pernah (1) }\end{array}$ & $\begin{array}{l}\text { Jarang } \\
(2)\end{array}$ & $\begin{array}{l}\text { Cukup } \\
\text { (3) }\end{array}$ & $\begin{array}{l}\text { Sering } \\
(4)\end{array}$ \\
\hline 1 & Apakah ada rasa nyeri di mulut? & & & & \\
\hline 2 & Apakah ada rasa nyeri di dagu? & & & & \\
\hline 3 & Apakah ada rasa nyeri di dalam mulut? & & & & \\
\hline 4 & Apakah tenggorok Anda sakit? & & & & \\
\hline 5 & Apakah ada gangguan menelan air? & & & & \\
\hline 6 & Apakah ada gangguan menelan makanan lunak? & & & & \\
\hline 7 & Apakah ada gangguan menelan makanan padat? & & & & \\
\hline 8 & Apakah Anda tersedak saat makan? & & & & \\
\hline 9 & Apakah ada gangguan pada gigi? & & & & \\
\hline 10 & Apakah Anda kesulitan membuka mulut lebar? & & & & \\
\hline 11 & Apakah ada rasa kering di mulut? & & & & \\
\hline 12 & Apakah ada rasa kental pada ludah? & & & & \\
\hline 13 & Apakah ada gangguan pada indera penciuman Anda? & & & & \\
\hline 14 & Apakah ada gangguan pada indera pengecapan? & & & & \\
\hline 15 & Apakah Anda batuk? & & & & \\
\hline 16 & Apakah suara Anda serak? & & & & \\
\hline 17 & Apakah Anda merasa sakit? & & & & \\
\hline 18 & Apakah penampilan Anda terasa mengganggu? & & & & \\
\hline 19 & Apakah Anda kesulitan saat makan? & & & & \\
\hline 20 & Apakah Anda kesulitan saat makan di depan keluarga? & & & & \\
\hline 21 & Apakah Anda kesulitan saat makan di depan orang lain? & & & & \\
\hline 22 & Apakah Anda kesulitan menikmati makanan? & & & & \\
\hline 23 & Apakah Anda kesulitan saat berbicara dengan orang lain? & & & & \\
\hline 24 & Apakah Anda kesulitan saat berbicara di telepon? & & & & \\
\hline 25 & $\begin{array}{l}\text { Apakah Anda kesulitan dalam berinteraksi sosial dengan } \\
\text { keluarga }\end{array}$ & & & & \\
\hline 26 & $\begin{array}{l}\text { Apakah Anda kesulitan dalam interaksi sosial dengan } \\
\text { teman? }\end{array}$ & & & & \\
\hline 27 & $\begin{array}{l}\text { Apakah Anda kesulitan saat berjalan-jalan di tempat } \\
\text { umum? }\end{array}$ & & & & \\
\hline 28 & $\begin{array}{l}\text { Apakah Anda kesulitan saat kontak fisik dengan keluarga } \\
\text { dan teman? }\end{array}$ & & & & \\
\hline 29 & Apakah Anda kurang tertarik berhubungan seks? & & & & \\
\hline \multirow[t]{2}{*}{30} & Apakah Anda kurang menikmati hubungan seks? & & & & \\
\hline & & & & Tidak (1) & Ya (2) \\
\hline 31 & $\begin{array}{l}\text { Apakah Anda menggunakan obat untuk menghilangkan } \\
\text { nyeri? }\end{array}$ & & & & \\
\hline 32 & Apakah Anda sudah minum suplemen (selain vitamin) & & & & \\
\hline 33 & $\begin{array}{l}\text { Apakah Anda menggunakan selang untuk makanan } \\
\text { (NGT) }\end{array}$ & & & & \\
\hline 34 & Apakah berat badan Anda turun? & & & & \\
\hline 35 & Apakah berat badan Anda bertambah? & & & & \\
\hline
\end{tabular}

